\title{
ИССЛЕДОВАНИЕ ПРОДУКТОВ ПИРОЛИЗА ПРИВИТЫХ СОПОЛИМЕРОВ ШЕРСТИ С ПОЛИАКРИЛОНИТРИЛОМ И ПОЛИСТИРОЛОМ
}

O. KIRRET, Aili KOGERMAN, Maret KRULL, Eha URBAS, I. BREUSSOVA. POLOAKROOLNITRIILI VOI POLUSTUROOLI JA VILLA KOPOLOMEERIDE POROLOOSI PRODUKTIDE ANALOUS

O. KIRRET, Aili KOGERMAN, Maret KRULL, Eha URBAS, I. BREUSSOVA. ANALYSIS OF PYROLYSIS PRODUCTS OF CO-POLYMERS OF WOOL WITH POLYACRYLNITRILE OR POLY. STYROLE

Одним из перспективных методов анализа полимеров является пиролитическая газовая хроматография (ПГХ): полимерное соединение подвергается термической деструкции в специальном устройстве (пиролизаторе), образующиеся летучие продукты анализируются хроматографически. ПГХ, при которой исследуемую полимерную систему характеризует спектр летучих продуктов пиролиза, используется в основном для быстрой идентификации полимеров ['], количественного анализа сополимеров $\left.{ }^{2}\right]$ и характеристики действия ингибиторов горения и термической деструкции [ $\left.{ }^{3}\right]$.

В данной работе с помощью ПГХ исследовались привитые сополимеры шерсти, содержащие цепи полиакрилонитрила (ПАН) и полистирола (ПСТ).

Методика. Пиролиз образцов шерсти $(0,5-2,0$ мг) проводился в специальном реакторе печного типа $\left[{ }^{4}\right]$ в течение 12 сек в токе инертного газа гелия. Продукты анализировались на хроматографе УХ-1 в колонках с активированным углем $\left(\mathrm{CO}\right.$ и $\left.\mathrm{CO}_{2}\right)$ и полиэтиленгликолем 1500 на хромосорбе $P$.

Синильная кислота в продуктах пиролиза определялась в колонке инертона $A W$ с $5 \%$-ным диметилсульфоланом хроматографа ПеркинЭльмер 900.

Обсуждение результатов. На рис. 1 приведены пирограммы образцов исходной шерсти, ПАН, ПСТ и привитых сополимеров шерсти с ПАН и ПСТ. Все они имеют характерный для данного материала контур, следовательно, методику ПГХ, применяемую для идентификации различных полимеров и статистических сополимеров, можно использовать и для идентификации привитых сополимеров.

В реальных условиях материалы в ходе эксплуатации подвергаются разовым термическим перегрузкам, поэтому их создателей всегда интересует состав летучих продуктов термической деструкции и особенно содержание вредных для человека летучих веществ. 

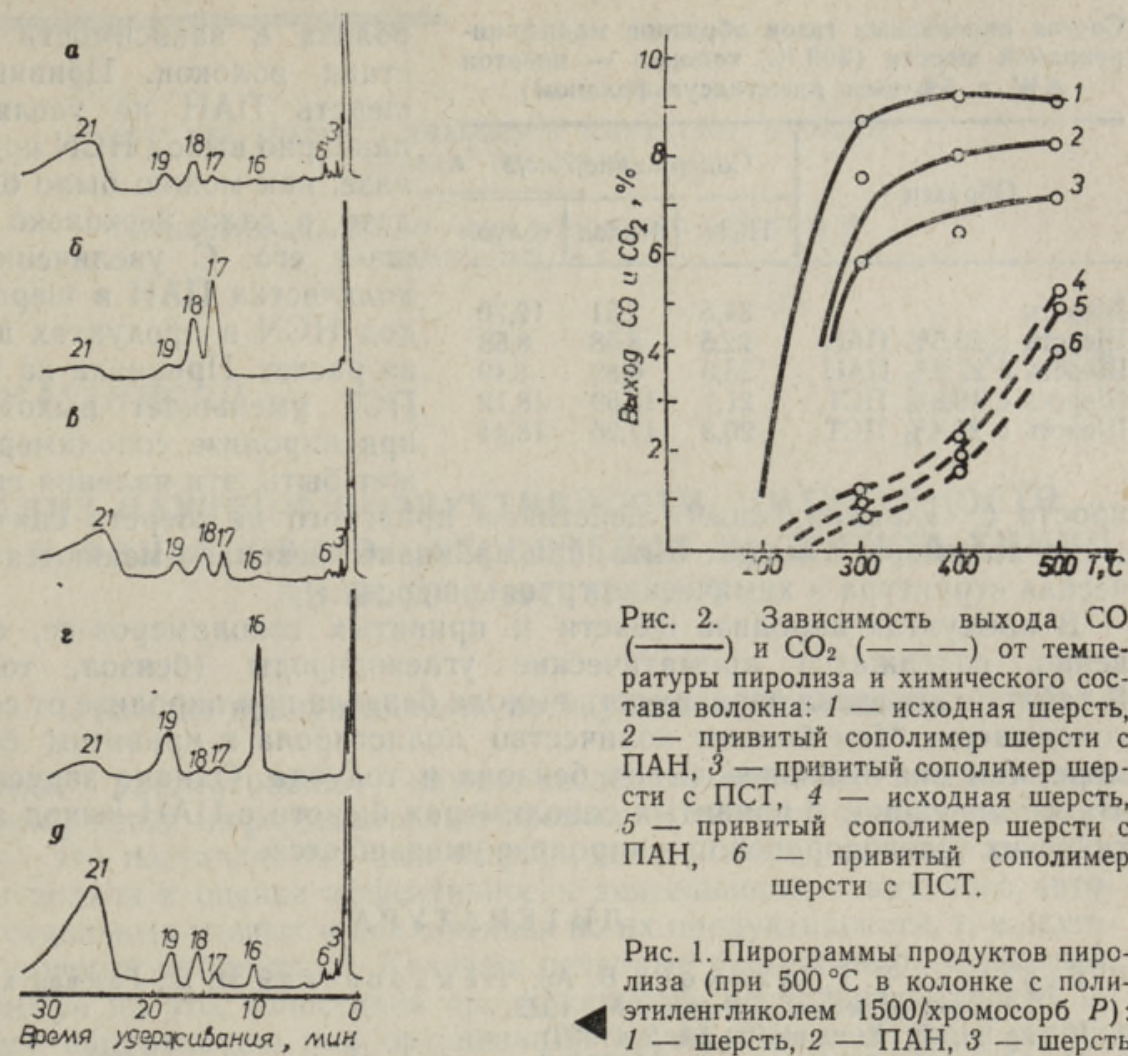

Рис. 2. Зависимость выхода СО $(-)$ и $\mathrm{CO}_{2}(---)$ от температуры пиролиза и химического состава волокна: 1 - исходная шерсть, 2 - привитый сополимер шерсти с ПАН, 3 - привитый сополимер шерсти с ПСТ, 4 - исходная шерсть, 5 - привитый сополимер шерсти с ПАН, 6 - привитый сополимер шерсти с ПСТ.

Рис. 1. Пирограммы продуктов пиролиза (при $500{ }^{\circ} \mathrm{C}$ в колонке с полиэтиленгликолем $1500 /$ хромосорб $P$ ): 1 - шерсть, 2 - ПАН, 3 - шерсть + ПАН, 4 - ПСТ, 5- шерсть + ПСТ.

$\mathrm{B}$ работе прежде всего определялся выход $\mathrm{CO}$ и $\mathrm{CO}_{2}$ в зависимости от температуры пиролиза и состава волокна (рис. 2). Пиролиз исходной шерсти начинается при температуре ниже $200^{\circ} \mathrm{C}$ с выделением $\mathrm{CO}_{2}$, немного выше $200^{\circ}$ в продуктах пиролиза появляется и СО. С повышением температуры выход $\mathrm{CO}$ и $\mathrm{CO}_{2}$ увеличивается, но образование СО и $\mathrm{CO}_{2}$ имеет, вероятно, разные механизмы. Прививка на шерсть синтетических полимеров (ПАН и ПСТ) несколько повышает температуру начала выделения газовых продуктов термической деструкции и несколько уменьшает выход их.

В продуктах термического разложения азотсодержащих полимеров и волокон всегда появляется синильная кислота. На рис. 3 дано содержание HCN в продуктах пи-

Рис. 3. Зависимость выхода $\mathrm{HCN}$ от состава привитого сополимера. $I$ - в случае привитого сополимера шерсти с ПАН, 2 в случае привитого сополимера шерсти с ПСТ, 3 - теоретический при пиролизе шерсти с ПАН, 4 - теоретический при пи-

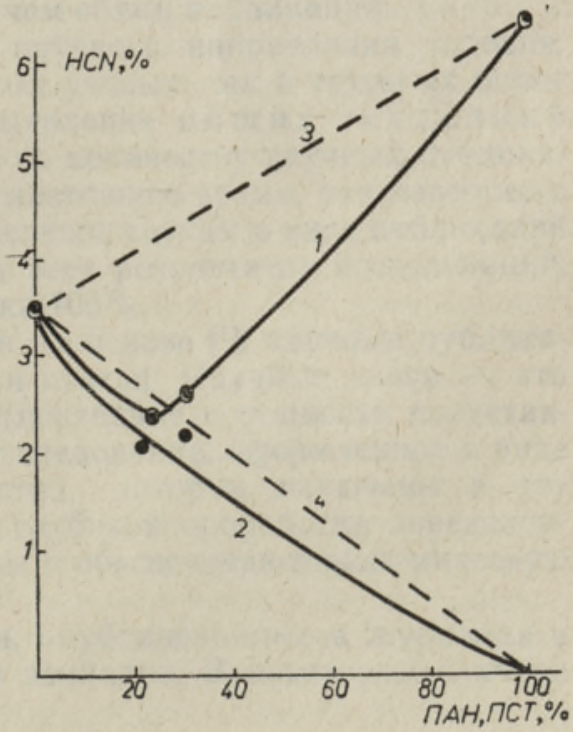
ролизе шерсти с ПСТ. 
Состав пиролизных газов образцов модифицированной шерсти $\left(900{ }^{\circ} \mathrm{C}\right.$, колонка - инертон $\boldsymbol{A} \boldsymbol{W}$ с $5 \%$-ным диметилсульфоланом)

\begin{tabular}{l|rrrr}
\hline \multirow{2}{*}{ Образец } & \multicolumn{3}{|c}{ Содержание, мг/2 } \\
\cline { 2 - 5 } & НСN & бензол & толуол \\
\hline Шерсть & 34,5 & 7,51 & 12,70 \\
Шерсть с 23,6\% ПАН & 22,5 & 8,58 & 8,58 \\
Шерсть с 27,8\% ПАН & 28,0 & 6,89 & 8,49 \\
Шерсть с 19,8\% ПСТ & 21,7 & 13,59 & 18,12 \\
Шерсть с 29,4\% ПСТ & 20,3 & 17,26 & 18,44
\end{tabular}

ролиза в зависимости от состава волокон. Прививка на шерсть ПАН не увеличивает линеарно выход HCN при пиролизе, как можно было бы ожидать, а даже несколько уменьшает его. С увеличением же количества ПАН в шерсти выход $\mathrm{HCN}$ в продуктах пиролиза растет. Прививка на шерсть ПСТ уменьшает выход $\mathrm{HCN}$ при пиролизе сополимера. Может быть, эти явления связаны просто с «экранирующим» действием привитого на шерсть синтетического полимера, а может быть, при прививке несколько меняются химическая структура и химические группы шерсти.

В продуктах пиролиза шерсти и привитых сополимеров ее, естественно, содержатся ароматические углеводороды (бензол, толуол). В таблице показана зависимость выхода бензола при пиролизе от состава сополимера. Чем больше количество полистирола в привитом сополимере, тем значительнее выход бензола и толуола. Однако зависимость эта не линеарна; в привитых сополимерах шерсти с ПАН выход ароматических углеводородов при пиролизе уменьшается.

\section{ЛИ Т Е Р А Т У Р А}

1. Березкин В. Г., Алишоев В. Ар., Неми иовская И. Б., Газовая хроматография в химии полимеров. М., 1972.

2. Voi g h t, J., Kunststoffe, 54, 2 (1963).

3. Hof fmann, P., Vortrag des SVCC-Symposium «Hochveredlung 1970» von 18.-20. 03. 1970. Zürich.

4. Кир рет О. Г., К юл ли к Э. А., Изв. АН ЭССР, сер. физ.-мат. и техн. н., 13, № 1, 15 (1964).

Институт химии

Академии наук Эстонской ССР
Поступнла в редакцию 15/IX 1977 